\title{
Transverse Crack Modeling and Validation in Rotor Systems Including Thermal Effects
}

\author{
N. Bachschmid, P. Pennacchi, and E. Tanzi \\ Dipartimento di Meccanica, Politecnico di Milano, Milano, Italy \\ S. Audebert \\ Recherche et Développement - Dép. Acoustique et Mécanique Vibratoire, EDF - Electricité de France, \\ Clamart, France
}

In this article, a model is described that allows one to simulate the static behavior of a transversal crack in a horizontal rotor, under the action of the weight and other possible static loads and the dynamical behavior of the rotating cracked shaft. The crack "breaths," i.e., the mechanism of opening and closing of the crack, is ruled by the stress acting on the cracked section due to the external loads; in a rotor the stress is time-depending with a period equal to the period of rotation, thus the crack "periodically breaths." An original simplified model is described that allows cracks of different shape to be modeled and thermal stresses to be taken into account, since they may influence the opening and closing mechanism. The proposed method has been validated using two criteria. Firstly, the crack "breathing" mechanism, simulated with the model, has been compared with the results obtained by a nonlinear 3-D FEM calculation and a good agreement in the results has been observed. Secondly, the proposed model allows the development of the equivalent cracked beam. The results of this model are compared with those obtained by the above-mentioned 3-D FEM. There is a good agreement in the results, of this case as well.

Therefore, the proposed crack model and equivalent beam model can be inserted in the finite beam element model used for the rotor dynamical behavior simulation-the obtained equations have time-depending coefficients, but they can be integrated in the frequency domain by using the harmonic balance method. The model is suitable for finite beam elements with six degrees of freedom per node, in order to

Received 25 June 2002; accepted 1 July 2002.

Address correspondence to P. Pennacchi, Dipartimento di Meccanica, Politecnico di Milano, Campus Bovisa, Via la Masa, 34, Milano, I-20158, Italy. E-mail: paolo.pennacchi@polimi.it account also for torsion vibrations and coupling between torsion and flexural vibrations.

Keywords Breathing effect, Crack modeling, Rotordynamics, Transverse crack, Thermal transient

The description of the dynamical behavior of horizontal heavy rotors presenting a transverse crack has been presented by many researchers (see e.g., the overviews of Wauer (1990), Gasch (1993), and Dimarogonas (1996)), particularly as regards to the "breathing mechanism." This characteristic behavior takes place during the rotor rotation: the crack moves from the upper position in which the static bending moment forces the crack to be "closed" to the opposite position in which the crack is forced to be "open." The gradually opening and closing of the crack is called the breathing mechanism. Therefore, the stiffness changes periodically during one rotation, and correspondingly, so does the static deflection due to the weight (and to the bearing alignment conditions). In fact, the stiffness of the rotor with the open crack is smaller with respect to the closed crack situation, in which the stiffness equals the value of the uncracked shaft. The periodical deflection and stiffness can both be expanded in a Fourier series, of which the most important components are the $1 \mathrm{x}, 2 \mathrm{x}$, and $3 \mathrm{x}$ rev. components. It can be shown that the same forces which excite the static deflection components also excite the dynamical vibrations when the shaft is rotating at higher speeds.

In addition to the effect of the static bending moments, thermal transients also have an influence on the breathing mechanism. Often, in real machines, the sudden change in vibrational behavior during thermal transients allowed, a crack in rotating shafts to be discovered. A case history is presented in Lapini et al. (1993) from which Figure 1 is derived. This shows the measured vibrations in a bearing of a cracked generator of a power plant, operating at rated speed, due to two thermal transients: first a 


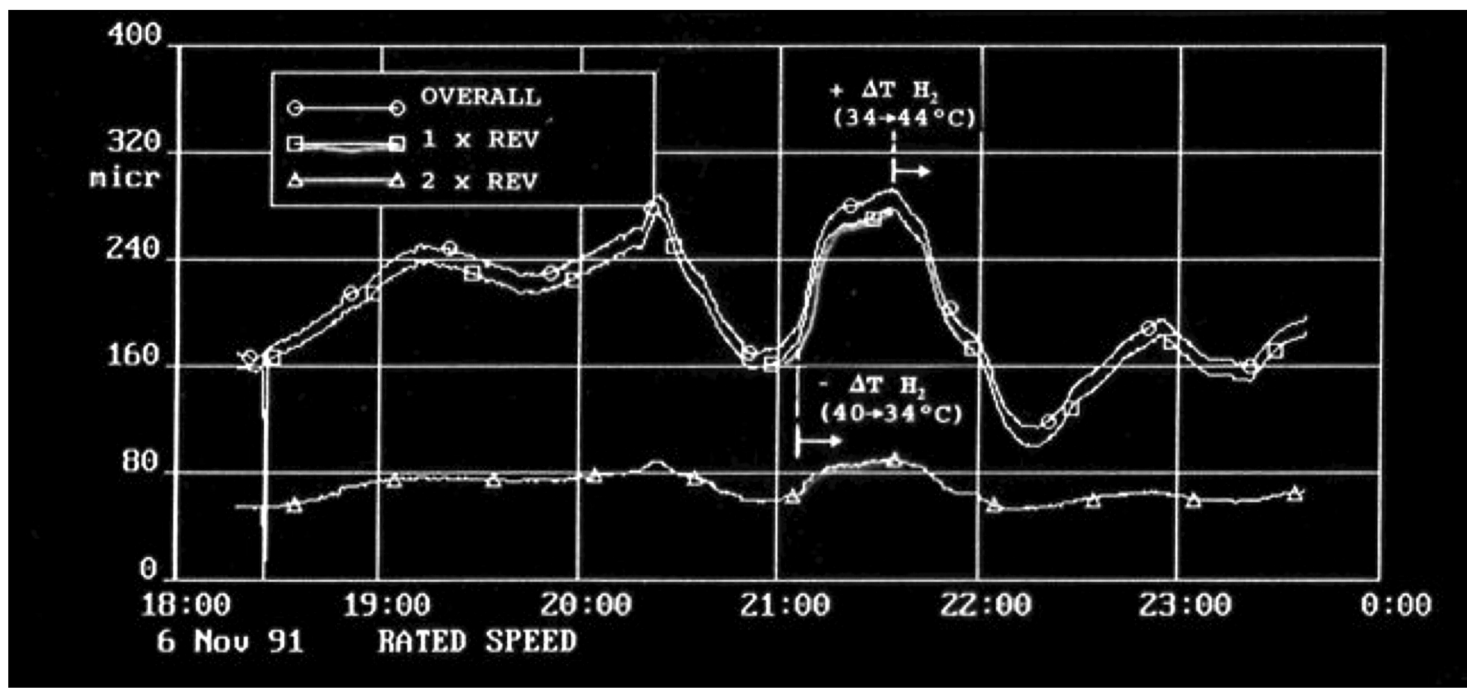

FIGURE 1

Cracked rotor thermal sensitivity.

cooling in the refrigerating fluid from $40^{\circ} \mathrm{C}$ to $34^{\circ} \mathrm{C}$, then a heating from $34^{\circ} \mathrm{C}$ to $44^{\circ} \mathrm{C}$. During the heating transient (a positive temperature gradient), compressive stresses arise on the "skin" of the shaft and tensile stresses in the "core" of the shaft. This has the following effects:

- If a local bow is presented in correspondence with the crack, due to the crack propagation, the thermal stresses reduce the existing bow and therefore a reduction in $1 \mathrm{x}$ rev. vibration component is obtained.

- The thermal stresses tend prevent and reduce the breathing behavior. Therefore a reduction of all components $(1 \mathrm{x}, 2 \mathrm{x}$, and $3 \mathrm{x}$ rev.) due to the breathing mechanism is generally obtained.

In the case of a cooling transient (a negative temperature gradient), the opposite situation with tensile stresses on the "skin" and compressive stresses on the "core" is obtained. This affects the crack in the following ways:

- A local bow is generated (or the existing local bow is increased) and the $1 \mathrm{x}$ rev. component of the vibrations due to the unbalance and to the bow is modified.

- The thermal stresses tend to hold the crack open. The breathing mechanism is modified and certainly an increase in $2 \mathrm{x}$ rev. component is expected.

Previous considerations suggest that a reliable model for crack breathing mechanism that also takes into account the effect of thermal transients would prove useful. A possible model is described in this article. First, a simplified 1-D model, which was already presented in Bachschmid et al. (2000), is described to determine the temperature distribution in a cylindrical rotor. Then, the stiffness changes in the cracked element of the ro- tor are described by introducing a 6 d.o.f. (degrees of freedom) per node model. The proposed models are validated by means of the comparison of the results obtained with 3-D f.e. (finite elemeents) calculations.

\section{THERMAL BEHAVIOR AND BREATHING MECHANISM OF CRACKED ROTORS}

To determine the temperature distribution, the equation of the thermal exchange is used in the case of axial-symmetry and of an infinite cylinder:

$$
\frac{\rho c_{p}}{k} \frac{\partial T}{\partial t}=\frac{1}{r} \frac{\partial}{\partial r} r \frac{\partial T}{\partial r}
$$

where $\rho$ is the density, $c_{p}$ the specific heat, $k$ the conduction coefficient, $r$ the radial coordinate, and $T$ the generic temperature of the section.

To solve the equation, the finite differences have been used with two different boundary conditions depending on the type of heat exchange:

a. In the case of convection on the external surface:

$$
\left.\frac{\partial T}{\partial r}\right|_{r_{i n t}}=\left.0 \quad k \frac{\partial T}{\partial r}\right|_{r_{e s t}}=H\left(T_{r_{e s t}}-T_{w}\right)
$$

where $H$ is the thermal exchange coefficient between steam or surrounding fluid and metal, $T_{\text {rest }}$ is the temperature of the external surface of the section, and $T_{w}$ is the fluid temperature.

b. In the case of an imposed temperature gradient $\Delta T / T$ on the external surface:

$$
\left.\frac{\partial T}{\partial r}\right|_{r_{i n t}}=0 \quad T_{r_{e s t}}(t+\Delta t)=T_{r_{e s t}}(t)+\Delta T
$$


If the number of the discretization points in the finite difference method and the time step $\Delta t$ are fixed and the material properties are considered as constant (at the average working temperature), the solving system is of the following type:

$$
\{T(t+\Delta t)\}=[A]\{T(t)\}
$$

where matrix $[A]$ has constant coefficients and $\{T(t+\Delta t)\}$ and $\{T(t)\}$ are the vectors of the temperatures in the radial coordinates determined over the section. Note that the radial coordinates have been chosen in order to divide the section in to rings with equal surface. Therefore, they are thinner close to the external surface.

By iterating Equation (4) with time step $\Delta t$, it is possible to determine the temperature distribution in each point of the section as a function of the time. The axial stress distribution corresponding to the temperature distribution is given by:

$$
\sigma=\frac{\alpha E}{1-v}\left(T_{m}-T(r)\right)
$$

where $\alpha$ is the linear thermal expansion, $E$ the Young's modulus, $v$ the Poisson's coefficient, $T(r)$ the temperature at the radial coordinate $r$, and $T_{m}$ the average section temperature. The effect of the centrifugal forces on the axial stresses has been neglected.

The thermal bow is calculated in the following way: The cracked areas in which no contact occurs cannot transmit stresses, therefore, the thermal stress distribution is no longer axial-symmetrical and the resulting moments $M_{B x}$ and $M_{B y}$ of this thermal stress distribution can be calculated with respect to the reference frame which is fixed to the beam. These moments, with opposite sign, are then applied to both ends of the equivalent beam of length $l_{c}$, which will be defined later, and generate the bow.

This procedure is obviously a rough approximate approach, since the actual stress distribution over the cracked area is completely different from that assumed by the proposed simplified

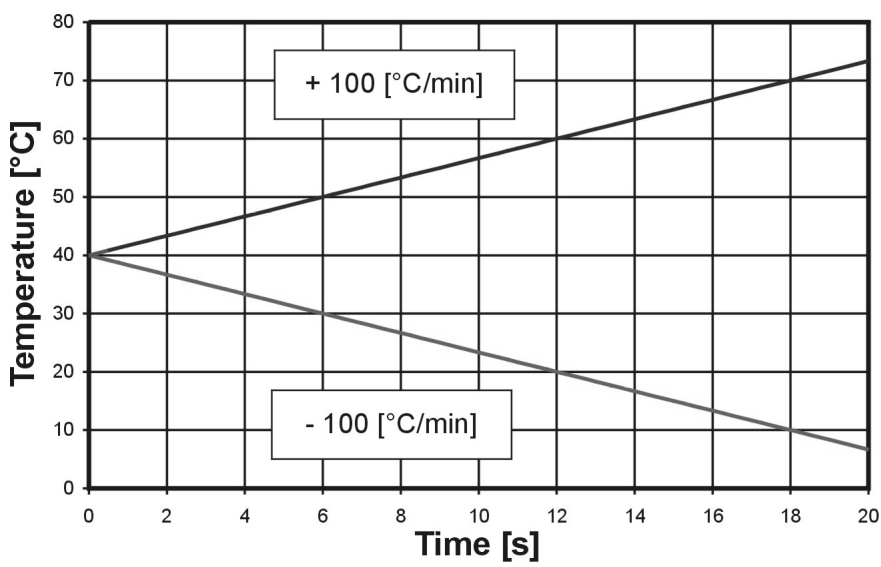

approach. However, it can be assumed that the bow depends on the uncompensated thermal stresses and the results confirm that the proposed procedure allows one to estimate the bow with satisfactory accuracy, as will be shown later.

The results obtained are different depending on short-time transients, in which the heating or cooling process involves more the outer skin of the beam than the whole body, or longtime transients, in which the complete body is interested by the temperature change and also high radial strains arise. With respect to the short transients, the stress distribution around the crack in long-lasting transients is different so as the deflections.

\section{NUMERICAL SIMULATIONS}

Some 1-D and 3-D calculations have been made on a round beam test specimen with a diameter of $25 \mathrm{~mm}$, and a long presenting a crack of $50 \mathrm{~mm}$ with a relative depth of $25 \%$ and $50 \%$ of the diameter. Furthermore, mechanical loads have been applied to an extension (on the left-hand side) in order to avoid local deformations due to load application. The loads were a bending moment of $10 \mathrm{Nm}$ and a torsion of $25 \mathrm{Nm}$.

Figure 2 shows the skin temperature and the corresponding axial stresses as a function of time for $\pm 100^{\circ} \mathrm{C} / \mathrm{min}$ temperature gradient, calculated with the 1-D model, starting from a uniform temperature distribution of $40^{\circ} \mathrm{C}$.

Figure 3 shows the temperature and the stress distribution over the cross section of the beam at $5 \mathrm{~s}$ for the $\pm 100^{\circ} \mathrm{C} / \mathrm{min}$ transient.

All these results have been obtained with the 1-D model, but the actual temperature and stress distributions, obtained by the 3-D model in cross sections that are unaffected by the crack and by the boundary conditions are quite similar.

Figures 4 and 5 represent the axial stress distribution on the longitudinal section of the cracked beam, clamped on the righthand side end: Figure 4 in the case of negative sharp transient $\left(-100^{\circ} \mathrm{C} / \mathrm{min}\right.$ in $\left.5 \mathrm{~s}\right)$ and Figure 5 in the case of positive sharp transient $\left(+100^{\circ} \mathrm{C} / \mathrm{min}\right.$ in $\left.5 \mathrm{~s}\right)$.

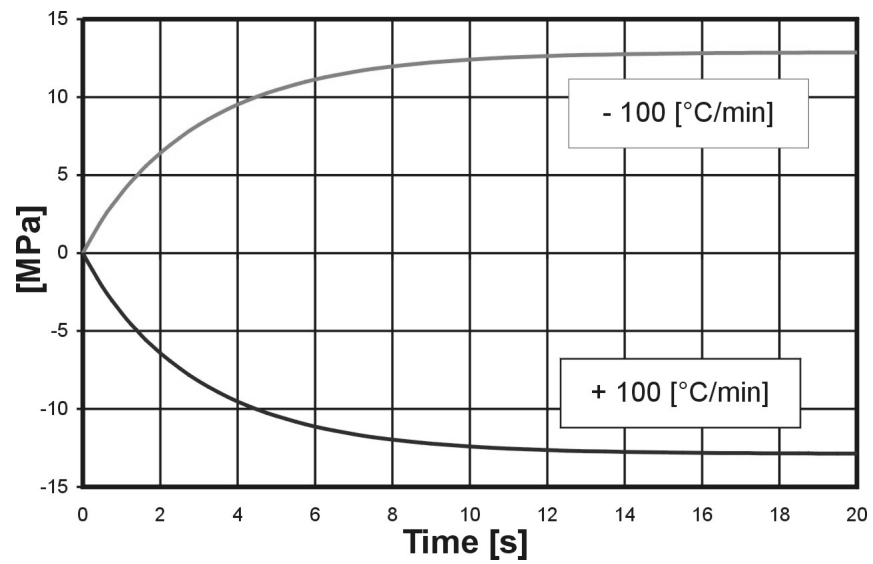

FIGURE 2

Skin temperature (left) and axial stresses (right) for temperature gradient of $\pm 100^{\circ} \mathrm{C} / \mathrm{min}$. 

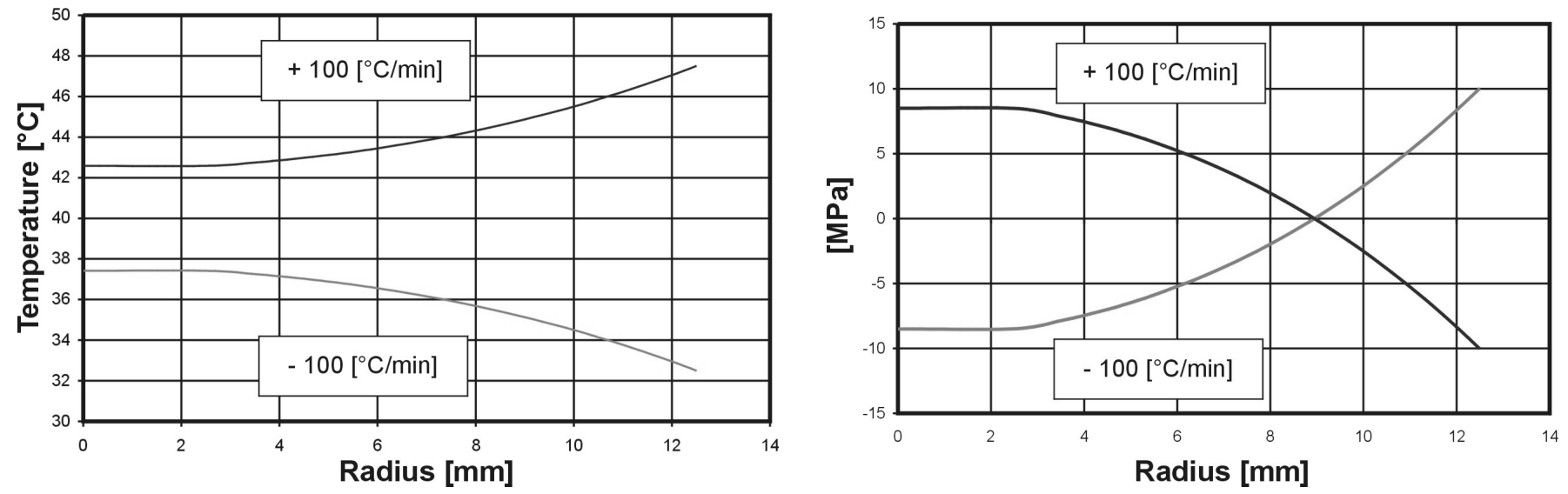

FIGURE 3

Internal temperatures (left) and axial stresses (right) for $\pm 100^{\circ} \mathrm{C} / \mathrm{min}$ gradient at time $5 \mathrm{~s}$.

The behavior is as expected. During the negative transient, the positive tensile stresses on the skin and the negative compression stresses on the internal part vanish in correspondence of the crack. The crack is completely open. This can be seen in Figure 6 which shows the relative axial displacements on the crack surface: only in the dark blue area are the relative displacements vanishing small, so that some contact could occur. Figure 7 shows the axial stresses on the cracked section; on the cracked surface the axial stress is roughly 0 , in the inner part a maximum compressive stresses of $11.8 \mathrm{MPa}$ is reached, and on the outer part, close to the crack tip, a maximum of tensile stress of $117 \mathrm{MPa}$ is reached. All these figures and some of the following have been obtained with the nonlinear 3-D model, for the crack of $50 \%$ depth.

During the positive transient, the negative compression stresses on the skin remain in correspondence with the crack, but, below that small portion, the rest of the crack has no stresses and is therefore open. Obviously, correspondence with the crack tip, very high tensile stress occur.

Figure 8 shows the stress distribution along the vertical diameter passing through the middle of the crack, in the case of positive and negative transients. This figure shows that the positive temperature transient effects the closure of the crack, as known from field experience. In fact, in a small area close to the skin, negative compression stresses appear. However, very high tensile stresses are generated at the crack tip (between 110 and

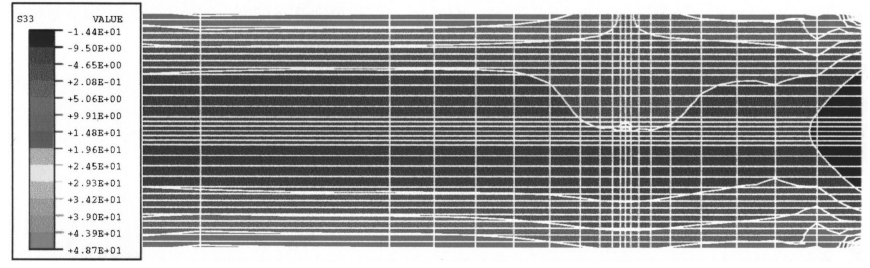

FIGURE 4

Axial stress distribution, cracked beam clamped at right-hand side, transient $-100^{\circ} \mathrm{C} / \mathrm{min}, 5 \mathrm{~s}$.
$120 \mathrm{MPa}$ ), which could be responsible for the propagation of the crack in many machines (turbogenerators) in which a slowly propagating crack has been found. This then happens when the rotor is heated during the start-up procedure.

In the simplified model, 1-D thermal stresses are simply superposed to stresses arising from mechanical loads; the nonlinear effects cannot be accounted for. Therefore, excellent agreement is found in all parts which are not close to the crack (and to the boundary), but poor agreement is found on the cracked section. Despite this, acceptable agreement is found in the breathing mechanism, as shown hereafter, and a rather good agreement has been found in the evaluation of the bow due to smooth or sharp temperature transients $\left( \pm 20^{\circ} \mathrm{C} / \mathrm{min}\right.$ and $\pm 100^{\circ} \mathrm{C} / \mathrm{min}$ ).

The deflections are calculated when the thermal transient is superposed to a mechanical load; this situation, which is always present in real machines, allows one to verify nonlinear effects in the superposition. In order to emphasize the thermal effect, the deflection due to the mechanical load alone has been subtracted. Only the position of external loads, which leads to open crack, has been considered.

From the results of Table 1, the following conclusions can be drawn.

- The behaviors corresponding to equal and opposite temperature gradients are symmetrical.

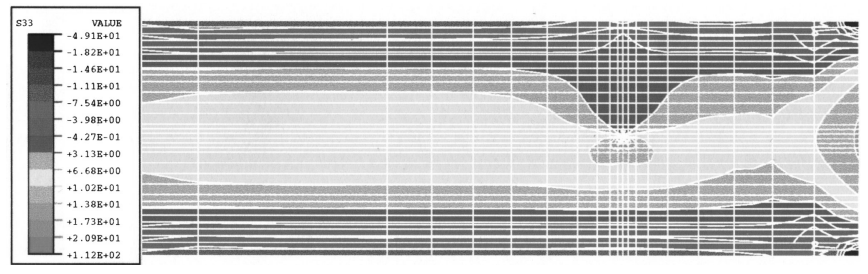

FIGURE 5

Axial stress distribution, cracked beam clamped at right-hand side, transient $+100^{\circ} \mathrm{C} / \mathrm{min}, 5 \mathrm{~s}$. 


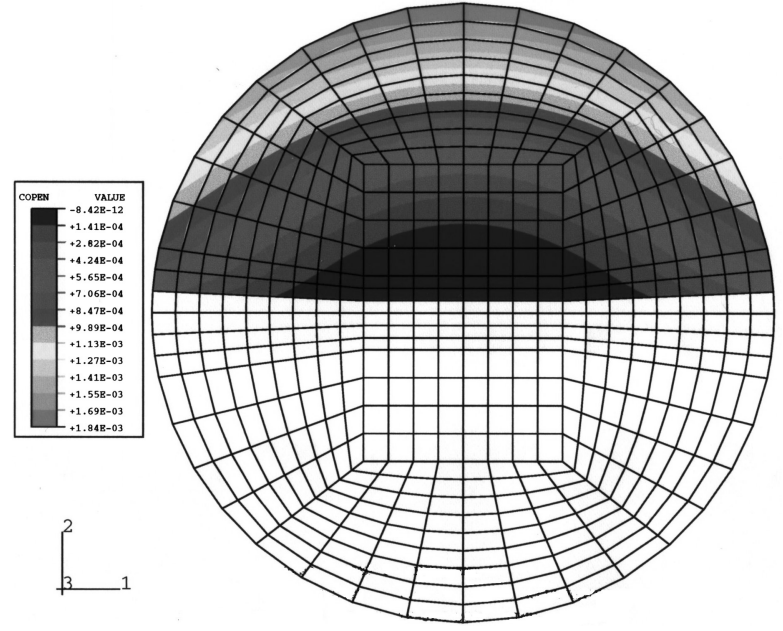

FIGURE 6

Relative axial displacements on crack surface.

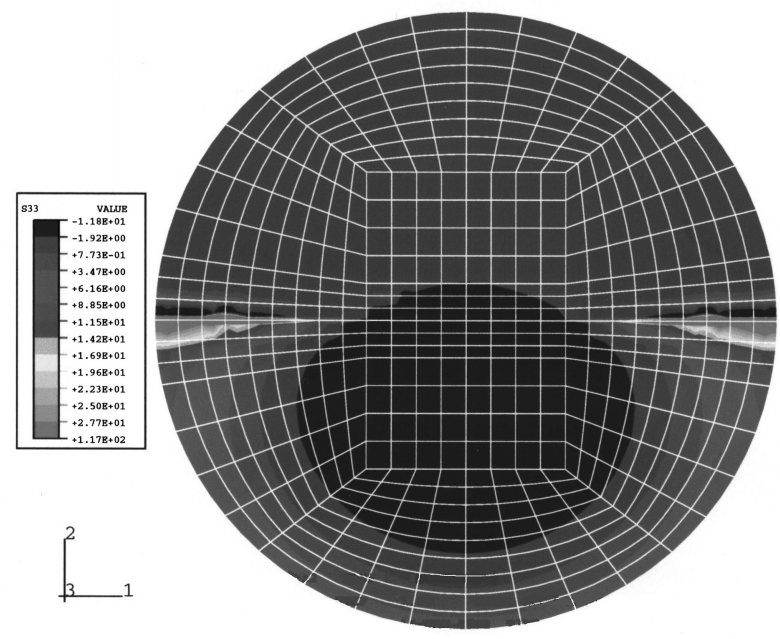

FIGURE 7

Axial stresses on cracked section.

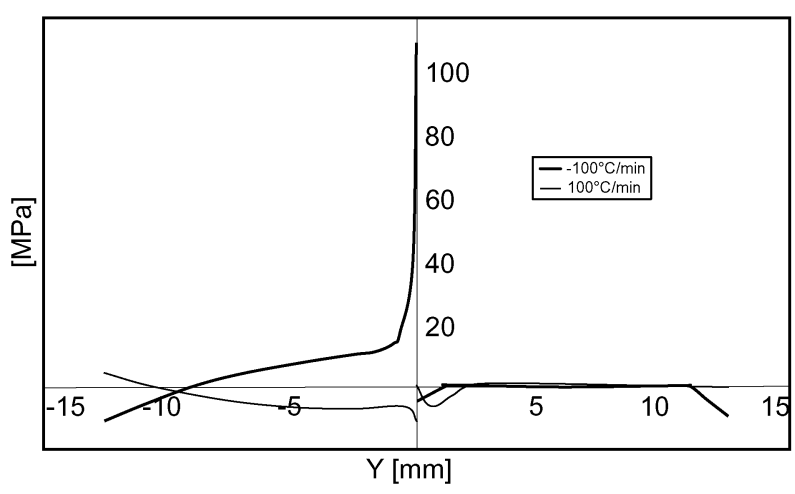

FIGURE 8

Stress distribution along the vertical diameter passing though the middle of the crack.
- The 1-D linear model systematically underestimates the deflections for deeper cracks (50\%) and for smaller cracks $(25 \%)$ in the case of the sharper temperature gradients,

- Since the errors introduced by the 1-D linear model are between a minimum of $+0.7 \%$ and a maximum of $23 \%$, the results can be considered a rough estimate of the actual behavior.

Other simulations show that when the cracked beam is without mechanical loads, loaded only by thermal stresses, then the symmetry of behavior is lost. Negative gradients produce the same deflections shown in Table 1, but positive gradients produce only very little deflections.

Thermal transients are considered long when the heat is propagated to the whole body of the beam. As said before, completely different stress and strain distributions can be found with respect to short transients. The axial stress distribution over the cross section of the beam, as obtained by the 1-D model with the smoother thermal transient $\left( \pm 20^{\circ} \mathrm{C} / \mathrm{min}\right)$ after $15 \mathrm{~min}$, is very similar to the one obtained for $\pm 100^{\circ} \mathrm{C} /$ min gradient after $5 \mathrm{~s}$ and represented in Figure 3.

Considering the $50 \%$ crack and the smoother thermal heating transient $\left(+20^{\circ} \mathrm{C} / \mathrm{min}\right)$ after $15 \mathrm{~min}$, the contact pressures shown in Figure 9 are obtained, to be compared with Figure 10 related to the same transient, but after $10 \mathrm{~s}$. Dark blue indicates no contact pressure. If the mechanical external load is superposed, then higher compressive stresses arise in the middle of the beam (the distribution over the cracked surface is shown in Figure 11). The behavior is therefore as would be expected.

\section{THE 1-D CRACK MODEL}

The proposed crack model is briefly described. The different steps for modeling the breathing behavior, including thermal effects, are the following:

1. The bending moment $M$, due to the weight and the bearing alignment conditions of the rotor, is calculated in correspondence to the cracked section.

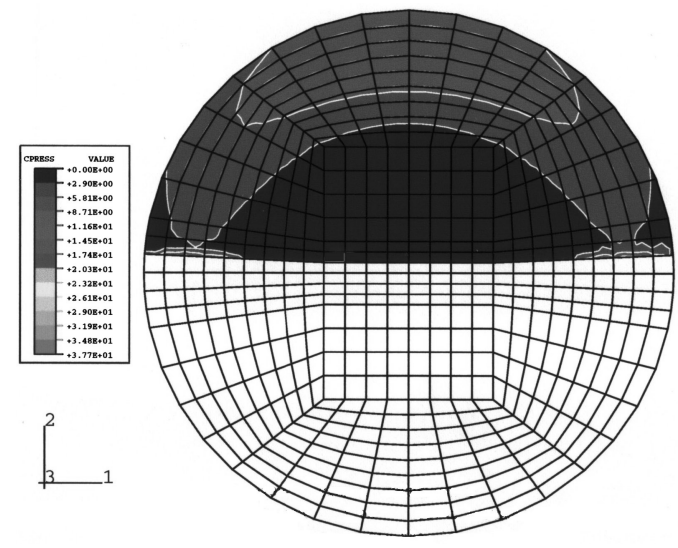

FIGURE 9

Contact pressure distribution, transient $+20^{\circ} \mathrm{C} / \mathrm{min}, 15 \mathrm{~min}$. 
TABLE 1

Comparison of deflections due to thermal stresses in $[\mu \mathrm{m}]$

\begin{tabular}{|c|c|c|c|c|c|c|c|c|}
\hline \multirow[b]{2}{*}{ Model } & \multicolumn{2}{|c|}{$+20^{\circ} \mathrm{C} / \mathrm{min}$} & \multicolumn{2}{|c|}{$-20^{\circ} \mathrm{C} / \mathrm{min}$} & \multicolumn{2}{|c|}{$+100^{\circ} \mathrm{C} / \mathrm{min}$} & \multicolumn{2}{|c|}{$-100^{\circ} \mathrm{C} / \mathrm{min}$} \\
\hline & $3 \mathrm{D}$ & 1D & $3 \mathrm{D}$ & 1D & $3 \mathrm{D}$ & 1D & $3 \mathrm{D}$ & 1D \\
\hline $25 \%$ crack & +0.133 & +0.135 & -0.133 & -0.134 & +0.541 & +0.433 & -0.571 & -0.459 \\
\hline $50 \%$ crack & +0.419 & +0.320 & -0.416 & -0.320 & +1.66 & +1.36 & -1.66 & -1.36 \\
\hline
\end{tabular}

2. One revolution of the shaft is divided into several part: In each position, following iterative calculations are performed on the discretized section shown in Figure 12, in order to define the open and closed sections of the cracked area, the position of the center of gravity $\mathrm{G}$ of the closed surface, the position of the main axis of inertia (angle $\vartheta$ ) with origin in $\mathrm{G}$, and the second area moments with respect to the main axis and the moments $M_{B x}, M_{B y}$ due to the thermal stress distribution.

2.1 Initially, the main axes $\left(x_{m}^{\prime}, y_{m}^{\prime}\right)$ are considered to be coincident with the rotating crack axes $(\vartheta=0)$; the stresses due to bending moment are calculated (with the assumed $x^{\prime} y^{\prime}$ main axis), and the thermal stresses are then added in each point.

2.2 Now the stress distribution is known over the cross section and the sign of the stress can be checked in each point of the cracked area: ' + ' means tension and therefore we have no contact forces in this point (the crack area element is "open"); '-' means compression and therefore we have contact forces (the crack area element is "closed"). The open and closed area sections have been determined.

2.3 The surface gravity center of the total area (formed by the uncracked area plus the closed cracked area) can be calculated.

2.4 The second moments of area can now be calculated with respect to the reference system with origin in $G$ and the

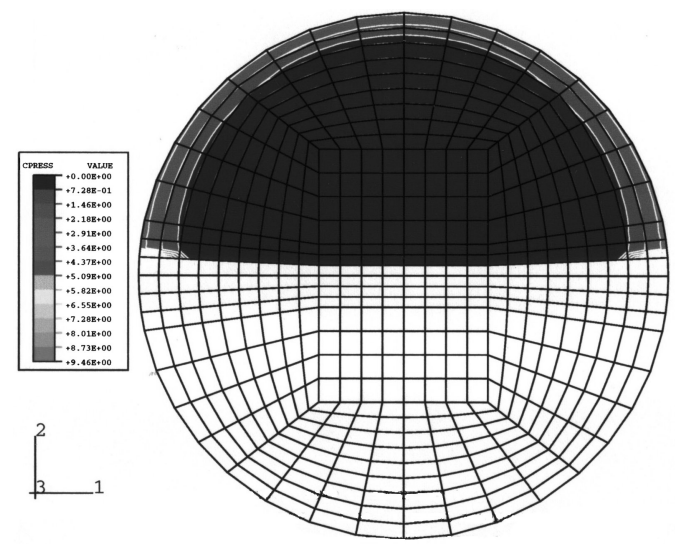

FIGURE 10

Contact pressure distribution, transient $+20^{\circ} \mathrm{C} / \mathrm{min}, 10 \mathrm{~s}$. angular position $\vartheta$ of the main axis of inertia can be found.

2.5 Now the procedure from 2.1 to 2.5 is repeated with the new value of $\vartheta$, until $\vartheta$ converges to a stable value.

3. At this point, the position of the main axis, the second moments of area and $M_{B x}, M_{B y}$, are known. The second moment of area $J_{x}, J_{y}$, and $J_{x y}$ with respect to the fixed reference frame (xy) and the components of the moments due to the thermal stress distribution $\left(M_{x}, M_{y}\right)$ with respect to the same reference frame, are calculated. This will be repeated for each angular position of the shaft.

The second moments of area, which are a function of the angular position, can then be used for calculating the stiffness $K_{c}(\Omega t)$ that is also a function of the angular position of the cracked beam element, which has a suitable length $l_{c}$. The moments of the thermal stress distribution are used for calculating the thermal bow.

\section{EQUIVALENT BEAM STIFFNESS MATRIX}

Once the breathing mechanism and the second moments of area have been defined for the different angular positions, the stiffness matrix of the cracked element of suitable length $l_{c}$ can be calculated, assuming a Timoshenko beam.

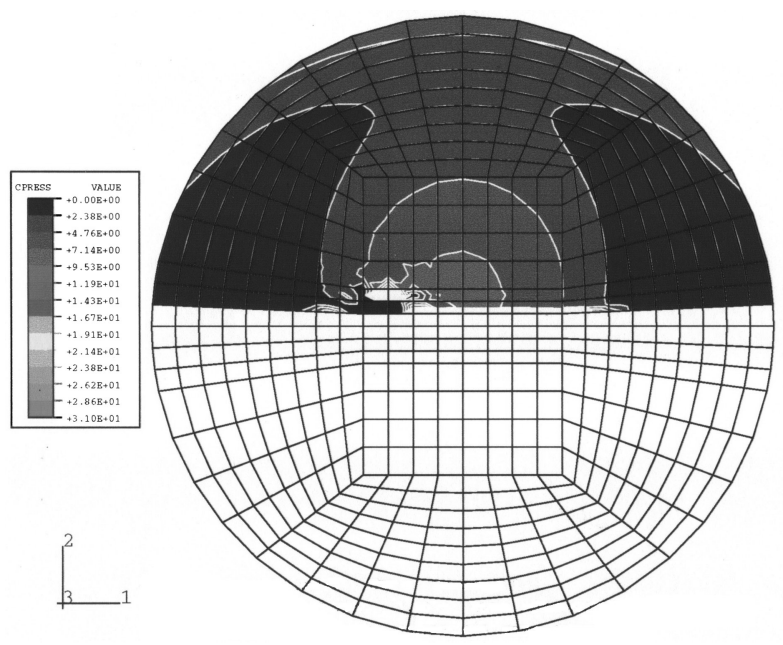

FIGURE 11

Contact pressure distribution over the cracked section, transient $+20^{\circ} \mathrm{C} / \mathrm{min}, 10 \mathrm{~s}$. 


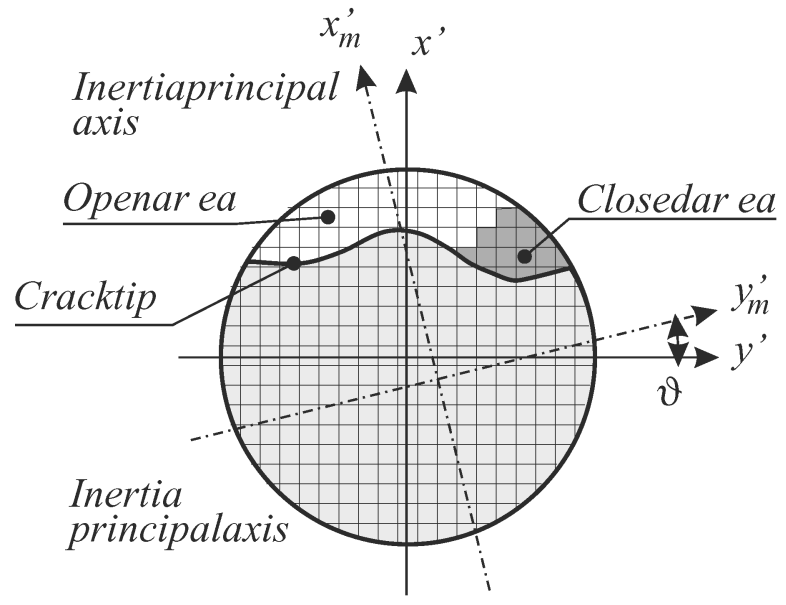

FIGURE 12

Cracked cross section.

The stiffness matrix (square, symmetrical, $12 \times 12$ elements) is represented in Equation (6):

$K_{c}\left(\Omega_{t}\right)\left\{\begin{array}{l}\mathbf{X}_{1} \\ \mathbf{X}_{2}\end{array}\right\}=$

$$
\left[\begin{array}{cccccccccccc}
a & c & p & q & w & m & -a & c & -p & q & -w & -m \\
& e & -q & r & i & 0 & -c & f & q & s & -i & 0 \\
& b & -d & k & n & -p & -q & -b & -d & -k & -n \\
& & h & j & 0 & -q & s & d & g & -j & 0 \\
& & & t & 0 & -w & -i & -k & -j & -t & 0 \\
& & & & u & -m & 0 & -n & 0 & 0 & -u \\
& & & & & a & -c & p & -q & w & m \\
& & & & & & e & q & r & i & 0 \\
& & & & & & & b & d & k & n \\
& & & & & & & & h & j & 0 \\
\vartheta_{y_{1}} \\
y_{1} \\
\vartheta_{x 1} \\
z_{2} \\
\vartheta_{y_{2}} \\
y_{2} \\
\vartheta_{x 2} \\
z_{2} \\
\vartheta_{z 2}
\end{array}\right\}
$$

where the coefficients are defined as:

$$
\begin{aligned}
& a=\frac{12 J_{y} E}{(1+\phi) l_{c}^{3}} \quad b=\frac{12 J_{x} E}{(1+\phi) l_{c}^{3}} \\
& c=\frac{6 J_{y} E}{(1+\phi) l_{c}^{2}} \quad d=\frac{6 J_{x} E}{(1+\phi) l_{c}^{2}} \\
& e=\frac{(4+\phi) J_{y} E}{(1+\phi) l_{c}} \quad f=\frac{(2-\phi) J_{y} E}{(1+\phi) l_{c}} \\
& g=\frac{(2-\phi) J_{y} E}{(1+\phi) l_{c}} \quad h=\frac{(4+\phi) J_{x} E}{(1+\phi) l_{c}} \\
& p=-\frac{6 J_{x y} E}{(1+\phi) l_{c}^{3}} \quad q=\frac{(1+\phi) l_{c}^{2}}{(4+\phi) J_{x y} E} \quad s=\frac{(2-\phi) J_{x y} E}{(1+\phi) l_{c}}
\end{aligned}
$$

$$
\begin{aligned}
t & =\frac{E A}{l_{a}} \quad u=\frac{G J_{p}}{l_{t}} \\
w & =t * X_{g} * c_{3} \quad k=-t * Y_{g} * c_{3} \\
m & =a * Y_{g T} * c_{1} \quad n=b * X_{g T} * c_{1} \\
i & =t * X_{g} * c_{2} \quad j=t * Y_{g} * c_{2}
\end{aligned}
$$

The parameter $\phi$ accounts for the shear effects and is given by:

$$
\phi=\frac{12 E J}{G S l_{c}^{2}}
$$

$E$ and $G$, respectively, are the Young's modulus and the shear modulus and $S$ is the cross section area. The different lengths $l_{c}$, $l_{a}$, and $l_{t}$ responsible for the direct stiffnesses and the parameters $c_{1}, c_{2}$, and $c_{3}$ responsible for the cross-coupling terms, have been tuned by means of the 3-D model.

The lengths $l_{c}, l_{a}$, and $l_{t}$ in some kind represent the extent to which the crack exerts his influence. The lengths are obviously related to the depth of the crack as shown, e.g., in Figure 13, where the relative length (ratio of length $l_{c}$ to diameter) is represented as a function of the relative depth (ratio of depth to diameter). The cracked element can then be introduced in the original beam element of length $l$. If the length $l$ is greater than the maximum value among $l_{c}, l_{a}$, and $l_{t}$, the stiffness of the element is easily calculated as also its deflection due to external loads in the different angular positions. If, on the contrary, the original element is shorter than the same maximum value, some additional processing of $K_{c}(\Omega t)$ is required, as shown below.

\section{DERIVATION OF LOCAL CRACK STIFFNESS}

The rotation-dependent stiffness matrix $K_{c}$ of a cracked beam element of length $l$ (Figure 14a) can be split into a stiffness matrix with three different parts: the stiffness of two equal uncracked beams of length $l / 2$ combined with a "local" stiffness part composed by "springs" which represent the crack (Figure 14b).

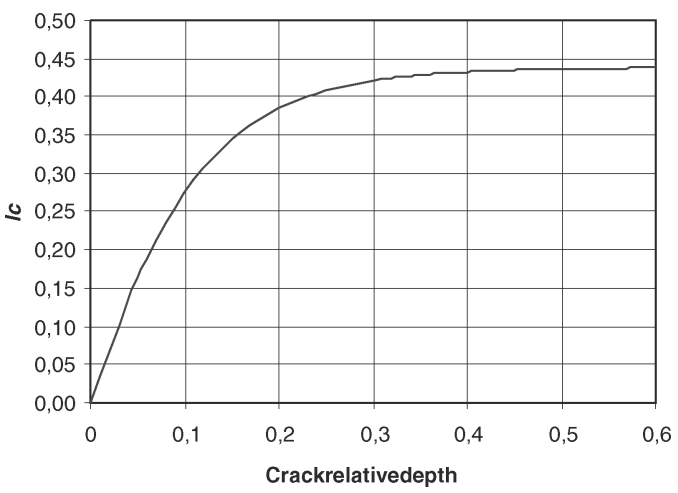

FIGURE 13

Equivalent length $l_{c}$ of the cracked beam. 


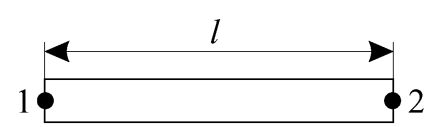

(a)

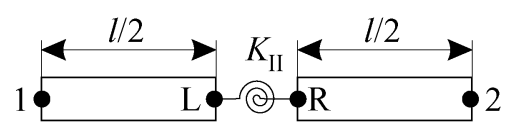

(b)

FIGURE 14

Cracked beam.

These springs have an infinite stiffness when the crack is closed and a finite stiffness when the crack is open. If we want to extract the local stiffness due to the crack from total stiffness, we have to introduce two additional nodes, namely nodes $L$ and $\mathrm{R}$, representing, respectively, the left- and right-hand sides of the crack faces.

Denoting by 1 the initial node of the cracked beam element, by 2 its final node, by $\mathbf{X}_{1}$ and $\mathbf{X}_{2}$ the vectors of the displacements of node 1 and 2 , respectively, we can consider $K_{c}$ a $12 \times 12$ matrix which leads to following equation:

$$
\left[K_{c}\right]\left\{\begin{array}{l}
\mathbf{X}_{1} \\
\mathbf{X}_{2}
\end{array}\right\}-\left[\begin{array}{ll}
{\left[K_{11}\right]} & {\left[K_{12}\right]} \\
{\left[K_{21}\right]} & {\left[K_{22}\right]}
\end{array}\right]\left\{\begin{array}{l}
\mathbf{X}_{1} \\
\mathbf{X}_{2}
\end{array}\right\}=\left\{\begin{array}{l}
\mathbf{F}_{1} \\
\mathbf{F}_{2}
\end{array}\right\}
$$

where $\mathbf{F}_{1}$ and $\mathbf{F}_{2}$ represent the force vectors applied to the end nodes of the beam. This matrix, being 1 and 2 external nodes of the beam, has to be distinguished from local crack stiffness $K_{\text {II }}$ (see Figure 14b) corresponding to nodes L and R:

$$
\left[K_{\mathrm{II}}\right]\left[\begin{array}{ll}
{\left[K_{\mathrm{LL}}\right]} & {\left[K_{\mathrm{LR}}\right]} \\
{\left[K_{\mathrm{LR}}\right]} & {\left[K_{\mathrm{RR}}\right]}
\end{array}\right]
$$

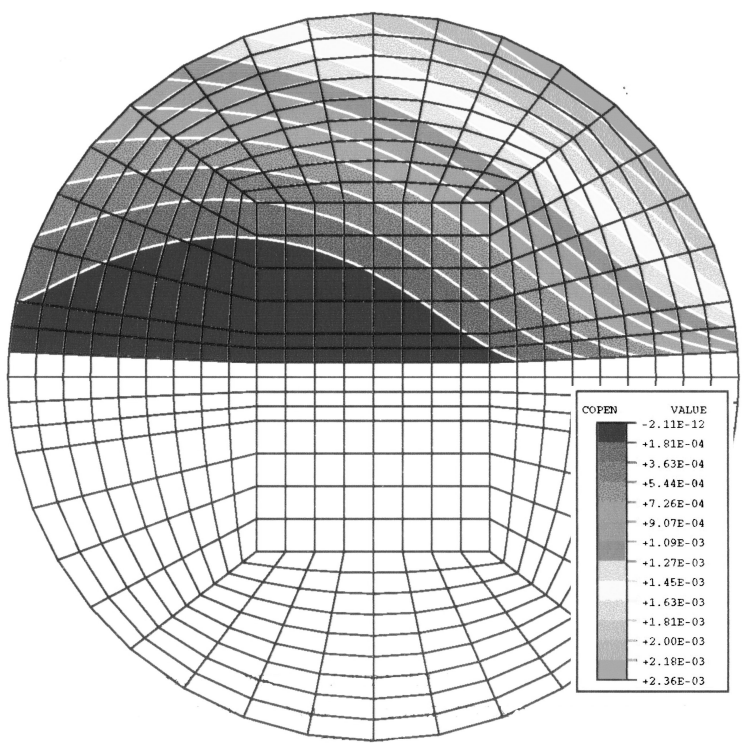

Considering the stiffness matrix according to (Figure 14b) we get the following structure:

$$
\left[\begin{array}{cccc}
{\left[K_{\mathrm{II}}\right]} & {\left[K_{\mathrm{IL}}\right]} & {\left[K_{\mathrm{IR}}\right]} & {\left[K_{12}\right]} \\
{\left[K_{\mathrm{LI}}\right]} & {\left[K_{\mathrm{LL}}\right]} & {\left[K_{\mathrm{LR}}\right]} & {\left[K_{\mathrm{L} 2}\right]} \\
{\left[K_{\mathrm{R} 1}\right]} & {\left[K_{\mathrm{RL}}\right]} & {\left[K_{\mathrm{RR}}\right]} & {\left[K_{\mathrm{R} 2}\right]} \\
\hline\left[K_{21}\right] & {\left[K_{2 \mathrm{~L}}\right]} & {\left[K_{2 \mathrm{R}}\right]} & {\left[K_{22}\right]}
\end{array}\right]\left\{\begin{array}{l}
\mathbf{X}_{1} \\
\mathbf{X}_{\mathrm{L}} \\
\mathbf{X}_{\mathrm{R}} \\
\mathbf{X}_{2}
\end{array}\right\}=\left\{\begin{array}{c}
\mathbf{F}_{1} \\
0 \\
0 \\
\mathbf{F}_{2}
\end{array}\right\}
$$

This matrix can be reordered considering the external (E) and internal (I) degrees of freedom. Calling

$$
\left\{\begin{array}{l}
\mathbf{X}_{1} \\
\mathbf{X}_{2}
\end{array}\right\}=\mathbf{X}_{\mathrm{E}},\left\{\begin{array}{l}
\mathbf{X}_{\mathrm{L}} \\
\mathbf{X}_{\mathrm{R}}
\end{array}\right\}=\mathbf{X}_{\mathrm{I}},\left\{\begin{array}{l}
\mathbf{F}_{1} \\
\mathbf{F}_{2}
\end{array}\right\}=\mathbf{F}_{\mathrm{E}}
$$

we get:

$$
\left[\begin{array}{c}
{\left[K_{\mathrm{EE}}\right]\left[K_{\mathrm{EI}}\right]} \\
{\left[K_{\mathrm{IE}}\right]\left[K_{\mathrm{II}}\right]}
\end{array}\right]\left\{\begin{array}{l}
\mathbf{X}_{\mathrm{E}} \\
\mathbf{X}_{1}
\end{array}\right\}=\left\{\begin{array}{c}
\mathbf{F}_{\mathrm{E}} \\
0
\end{array}\right\}
$$

where $K_{\mathrm{EI}}$ and $K_{\mathrm{IE}}$ are the stiffness matrices of the uncracked beam elements of length $l / 2$. Therefore $K_{\text {II }}$ can be extracted according to the following procedure: combining Equation (13) with Equation (17)

$$
\begin{aligned}
& K_{c} \mathbf{X}_{\mathrm{E}}=\mathbf{F}_{\mathrm{E}} \\
& K_{\mathrm{EE}} \mathbf{X}_{\mathrm{E}}+K_{\mathrm{EI}} \mathbf{X}_{\mathrm{I}}=\mathbf{F}_{\mathrm{E}} \\
& K_{\mathrm{IE}} \mathbf{X}_{\mathrm{E}}+K_{\mathrm{II}} X_{\mathrm{I}}=0 \\
& \mathbf{X}_{\mathrm{I}}=\mathbf{K}_{\mathrm{II}}^{-1}\left(-K_{\mathrm{IE}} \mathbf{X}_{\mathrm{E}}\right) \\
& \left.\left[K_{\mathrm{EE}}-K_{\mathrm{EI}} K_{\mathrm{II}}^{-1} K_{\mathrm{IE}}\right)\right] \mathbf{X}_{\mathrm{E}}=K_{\mathrm{c}} \mathbf{X}_{\mathrm{E}}
\end{aligned}
$$

from which we extract $K_{\mathrm{II}}$ :

$$
K_{\mathrm{II}}=\left[K_{\mathrm{EI}}^{-1}\left(K_{\mathrm{EE}}-K_{c}\right) K_{\mathrm{IE}}^{-1}\right]^{-1}
$$

FIGURE 15a

$50 \%$ depth crack, after $5 \mathrm{~s}$, temperature transient on the outer surface $-100^{\circ} \mathrm{C} / \mathrm{min}$, with external loads, angle $90^{\circ}$. 

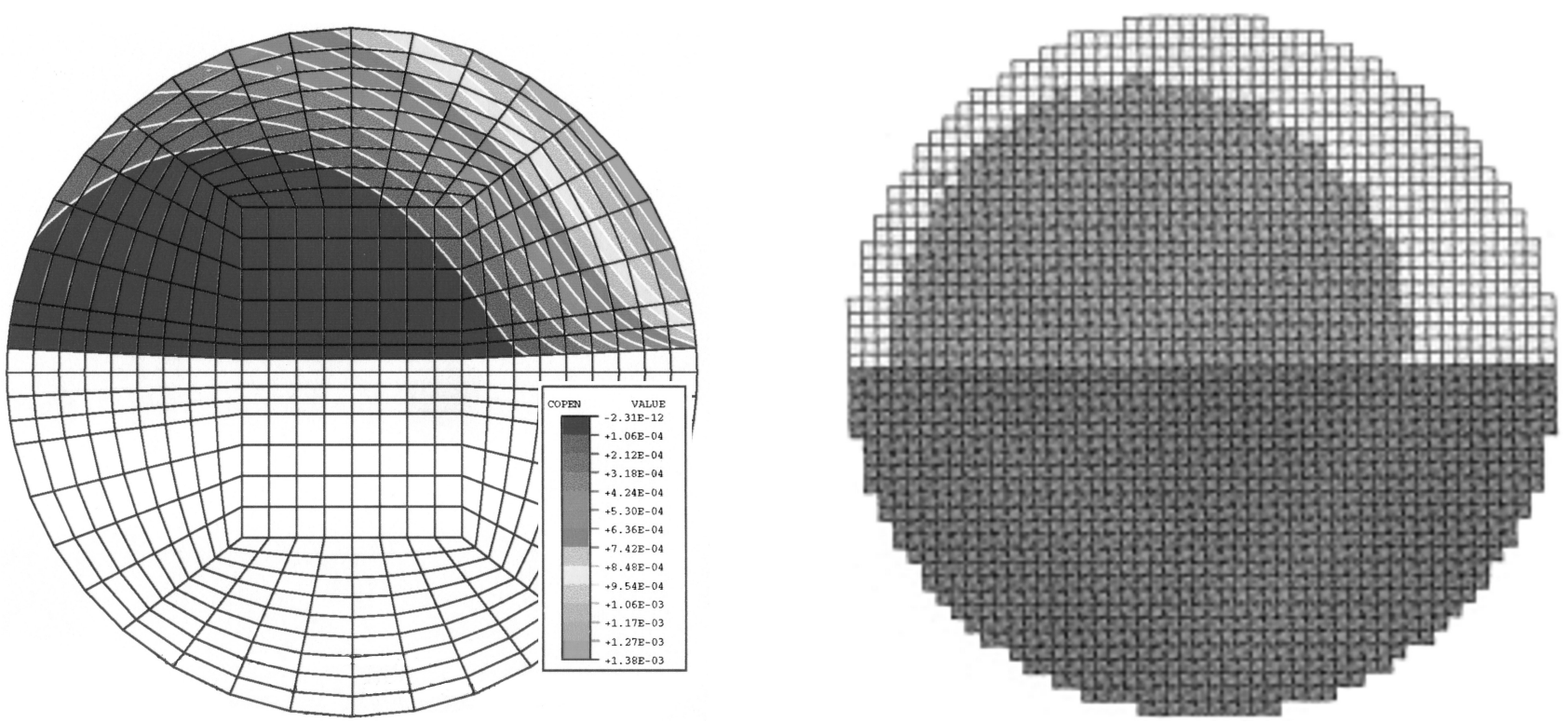

FIGURE 15b

$50 \%$ depth crack, after $5 \mathrm{~s}$, temperature transient on the outer surface $-100^{\circ} \mathrm{C} / \mathrm{min}$, with external loads, angle $120^{\circ}$.

It is interesting to note that the resulting local stiffness matrix $K_{\text {II }}$ does not show coupling terms between rotations and deflections, which instead exist in matrix $K_{c}$. This result was expected, considering that the local stiffnesses refer to a "beam" with zero length.

The local stiffness matrix can then be introduced in the cracked beam element remaining any restriction about the length of the element. The bow which has been calculated with the equivalent length $l_{c}$ beam generates a relative angular deflection of the end nodes: the same relative angular deflection can be applied directly to the crack faces, in the local crack model.

\section{BREATHING MECHANISM MODEL VALIDATION WITH TEMPERATURE GRADIENTS}

Positive and negative gradients have been considered, and their effects on 25 and 50\% depth cracks. Since the dimensions of the model are small, and the maximum statical bending stress
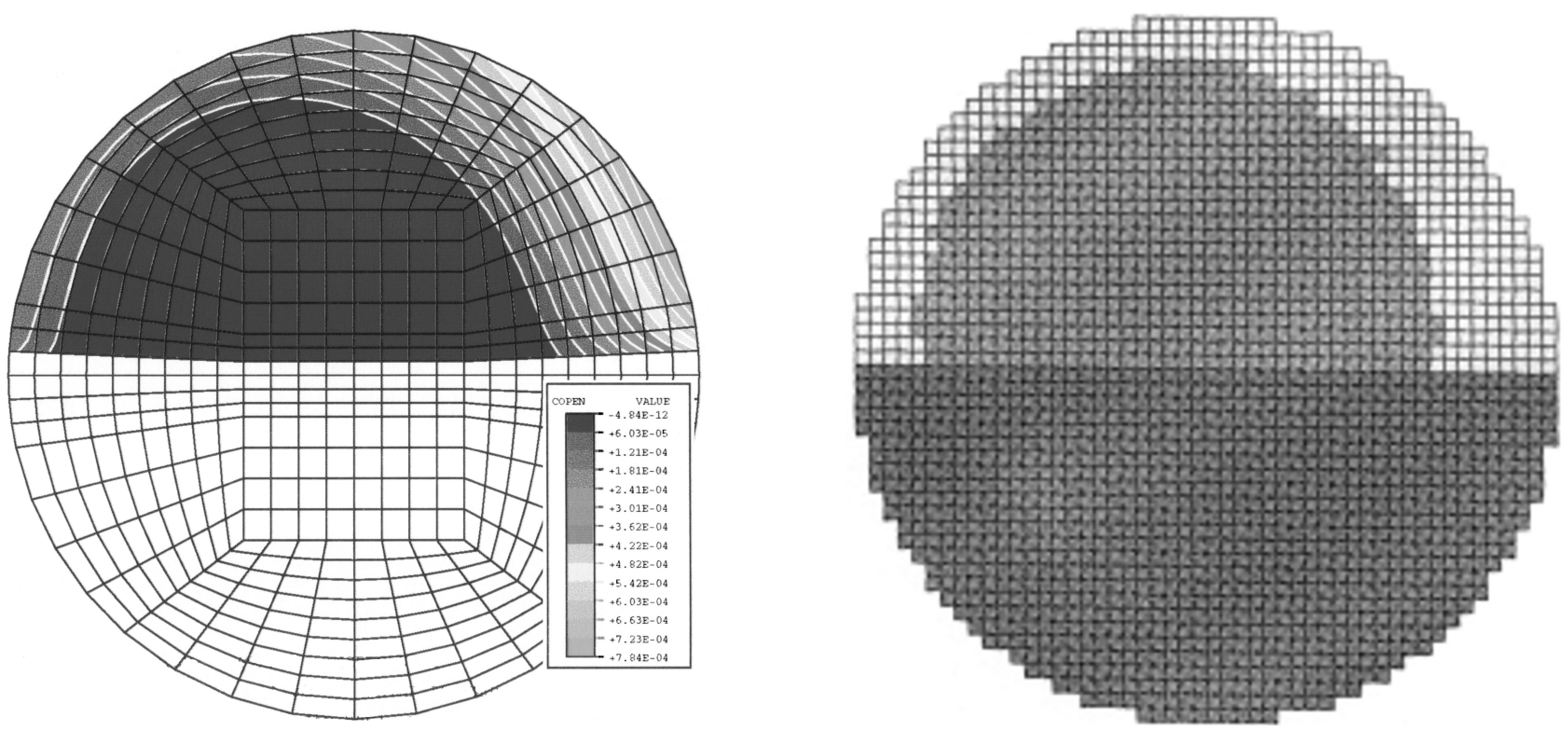

FIGURE 15c

$50 \%$ depth crack, after $5 \mathrm{~s}$, temperature transient on the outer surface $-100^{\circ} \mathrm{C} / \mathrm{min}$, with external loads, angle $150^{\circ}$. 

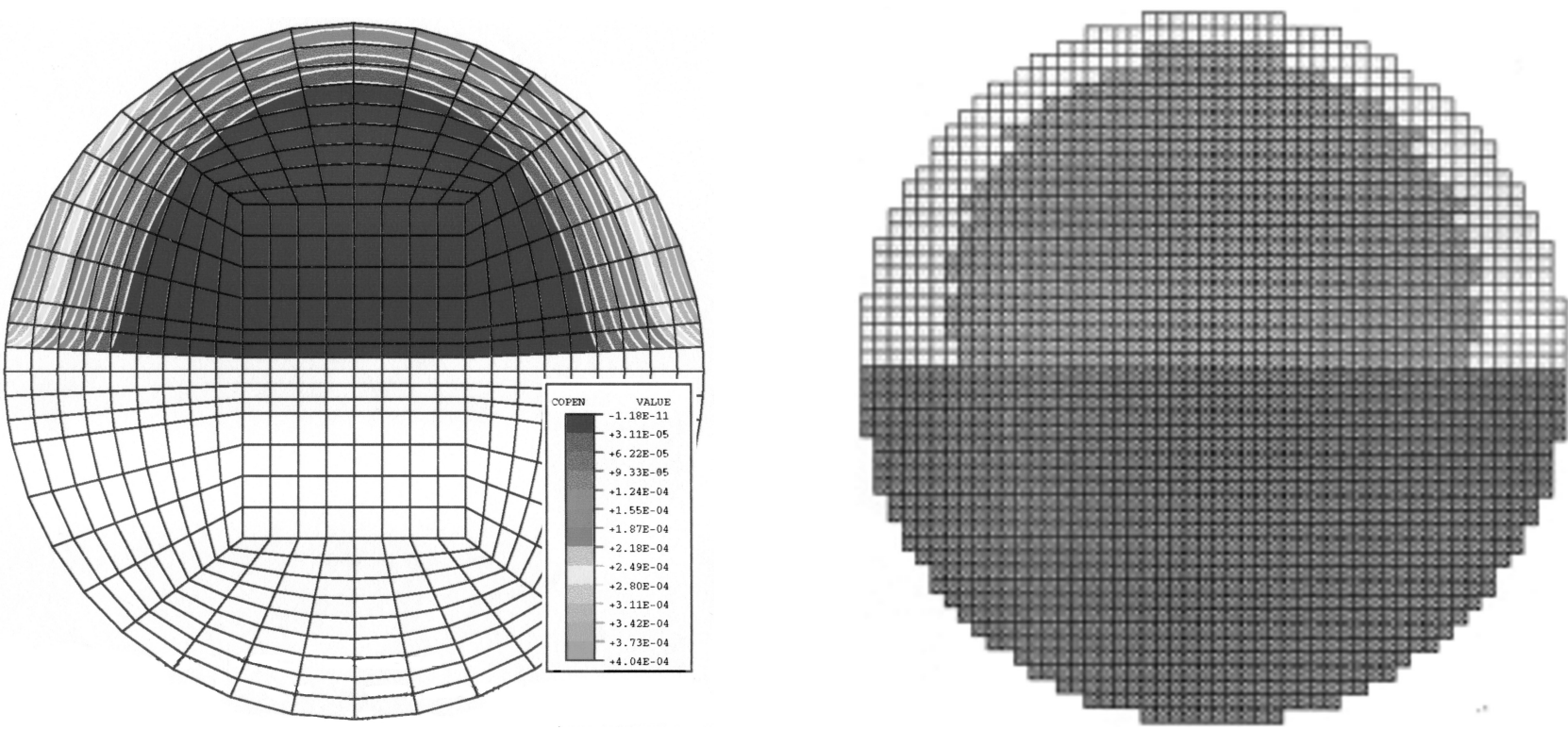

FIGURE 15d

$50 \%$ depth crack, after $5 \mathrm{~s}$, temperature transient on the outer surface $-100^{\circ} \mathrm{C} / \mathrm{min}$, with external loads, angle $180^{\circ}$.

reach $6.5 \mathrm{~N} / \mathrm{mm}^{2}$, a rather robust thermal transient has been applied, in order to generate stresses of the same order of magnitude.

Constant gradients of $\pm 100^{\circ} \mathrm{C} / \mathrm{min}$ and $\pm 20^{\circ} \mathrm{C} / \mathrm{min}$ have been applied to the external surface of the cylinder and the resulting stresses and the breathing behavior have been calculated after 5 and $10 \mathrm{~s}$, respectively.

If the external load (bending + torsion) is superposed to the thermal load, the following figure is obtained for the $50 \%$ depth crack and the sharper temperature transient $\left(-100^{\circ} \mathrm{C} / \mathrm{min}\right.$ after $5 \mathrm{~s}$ ): Figure 15 shows the situation corresponding to the following angular positions of $90^{\circ}, 120^{\circ}, 150^{\circ}$, and $180^{\circ}$.

For smaller angles, the crack is completely open; for angles from 180 to $360^{\circ}$ a symmetrical behavior is found, as expected. Similar results are obtained for other crack depths and other thermal transients. Note that the dark blue zones indicate zones in which contact between the crack faces occurs.

Although the agreement is not so good as in the case of only mechanical loading, it can be considered satisfactory, bearing in mind that the actual stress distribution over the cracked section deviates strongly from superposition of stresses used by the simplified linear model.

\section{CONCLUSIONS}

The thermal behavior of cracked round beams has been analyzed by means of a 3-D nonlinear model. The temperature distribution is unaffected by the crack, but the stress and strain distributions are strongly influenced by the crack. This results in a bow of the beam.

A 1-D model for calculating temperature and axial stress distributions in an infinite cylinder is presented and the results of the axial stress distribution are used for calculating thermal bows, by means of a rough approximation. The acceptable agreement with results obtained by means of the 3-D nonlinear model, validates the proposed procedure.

Furthermore, a 1-D crack model has been described that allows cracks of different shapes to be modeled and thermal stresses to be taken into account. The breathing mechanism obtained with this 1-D model has been validated with 3-D nonlinear calculations. The obtained good agreement allows one to propose the 1-D model as a powerful tool for cracked rotor analysis.

\section{ACKNOWLEDGMENTS}

This work is partially funded by the MURST (Italian Ministry for the University and Scientific Research) Cofinanziamento "Identificazione di Malfunzionamenti in Sistemi Meccanici" for the year 1999.

\section{NOMENCLATURE}

$c_{1}, c_{2}, c_{3}$ cross-coupling stiffness coefficient tuning parameters

$\begin{array}{ll}c_{p} & \text { specific heat } \\ E & \text { Young's modulus } \\ \mathbf{F} & \text { force vector } \\ G & \text { shear modulus } \\ H & \text { thermal exchange coefficient } \\ J_{x}, J_{y}, J_{x y} & \begin{array}{l}\text { second moments of area } \\ k\end{array} \\ K & \text { conduction coefficient } \\ K_{c} & \text { stiffness matrix } \\ l & \text { stiffness matrix of cracked beam element } \\ & \text { beam length }\end{array}$




$\begin{array}{ll}l_{a} & \begin{array}{l}\text { equivalent length for the axial stiffness } \\ \text { length of the equivalent beam used to model the } \\ \text { crack }\end{array} \\ l_{t} & \begin{array}{l}\text { equivalent length for the torsional stiffness } \\ \text { bending moments due to the weight and bearing } \\ \text { alignment conditions of the rotor }\end{array} \\ M_{x}, M_{y} & \begin{array}{l}\text { bending moments due to thermal stress distribution, } \\ \text { with respect to the fixed reference }\end{array} \\ M_{B x}, M_{B y} & \begin{array}{l}\text { bending moments due to thermal stress distribution, } \\ \text { with respect to the main axes }\end{array} \\ r & \text { radial coordinate } \\ T & \text { temperature } \\ T_{m} & \begin{array}{l}\text { average section temperature } \\ \text { temperature of the external surface }\end{array} \\ T_{\text {rest }} & \text { fluid temperature } \\ T_{w} & \text { fixed reference frame } \\ x, y & \text { reference system fixed on the rotor } \\ x^{\prime}, y^{\prime} & \text { main axes } \\ x_{m}^{\prime}, y_{m}^{\prime} & \text { displacement vector } \\ \mathbf{X} & \text { coordinates of the center of area of the section } \\ X_{g}, Y_{g} & \text { coordinates of the center of area of the section that } \\ X_{g T}, Y_{g T} & \text { participates to the torsion } \\ \alpha & \text { linear thermal expansion }\end{array}$

$\vartheta \quad$ angular position of main axis of inertia

$v \quad$ Poisson's coefficient

$\phi \quad$ parameter of the shear effect

$\rho \quad$ density

$\sigma \quad$ axial stress

\section{REFERENCES}

Bachschmid, N., Vania, A., and Audebert, S. 2000. A comparison of different methods for transverse crack modeling in rotor system. Proceedings of ISROMAC-8 Conference, March 26-30, Honolulu, Hawaii, 1057-1064.

Dimarogonas, A. D. 1996. Vibration of cracked structures: a state of the art review. Engineering Fracture Mechanics 55(5):831857.

Gasch, R. 1993. A survey of the dynamic behaviour of a simple rotating shaft with a transverse crack. Journal of Sound and Vibration 160(2):313-332.

Lapini, G. L., Zippo, M., Bachschmid, N., Collina, A., and Vallini, A. 1993. Experimental tests and model based calculations for the diagnosis of a crack in 320 MW generator, in Diagnostics of Rotating Machines in Power Plants, Diana, G., Ed., Springer-Verlag, WienNew York.

Wauer, J. 1990. On the dynamics of cracked rotors: a literature survey. Applied Mechanics Review 3:13-17. 

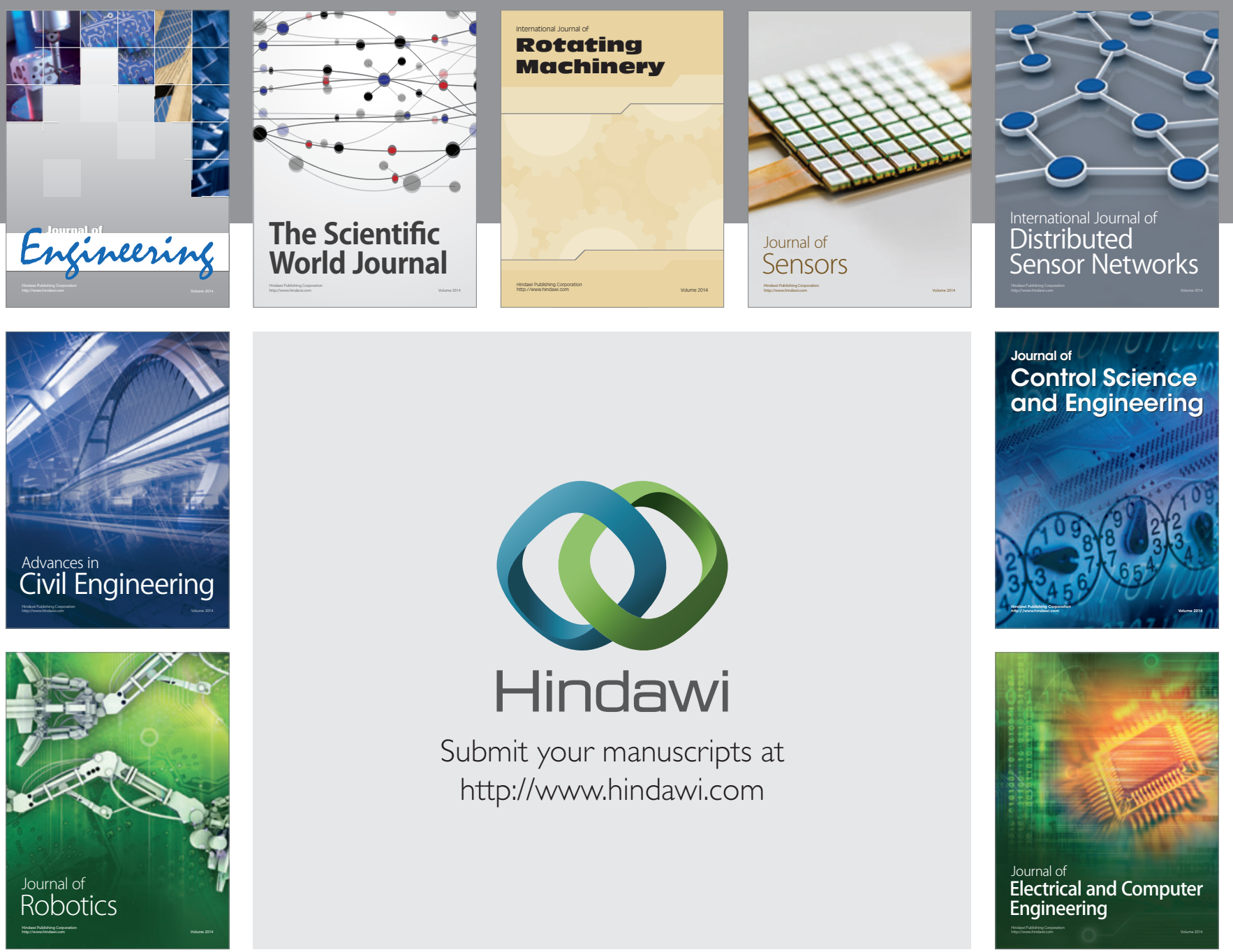

Submit your manuscripts at

http://www.hindawi.com
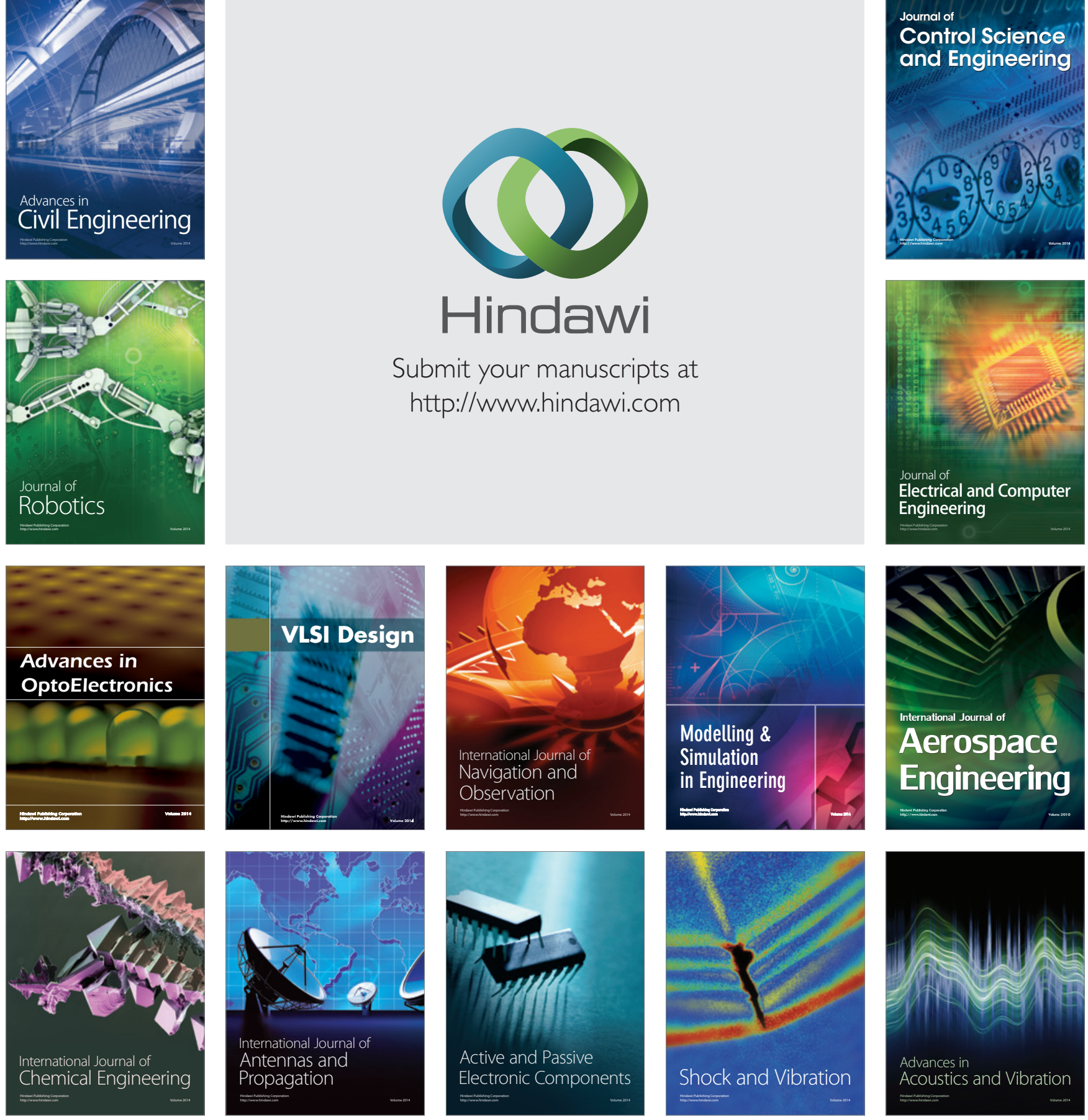